\title{
Predatory Publishing: An Industry that Is Threatening Science
}

\section{Predatory Publishing: Uma Indústria que Está a Ameaçar a Ciência}

Joana REVÉS $\triangle^{1,2}$, Bernardo Marques da SILVA ${ }^{3,4,5}$, José DURÃO ${ }^{4,5}$, Nuno Vouga RIBEIRO ${ }^{4,5}$, Samuel LEMOS ${ }^{4,6}$, Pedro ESCADA 7,8

Acta Med Port 2018 Mar;31(3):141-143 - https://doi.org/10.20344/amp.9810

Keywords: Open Access Publishing; Publishing

Palavras-chave: Publicação; Publicação em Acesso Livre

\section{What is predatory publishing?}

Scientific publication was introduced in 1665 with the creation of the journal Philosophical Transactions of the Royal Society, and its purpose was to develop a concept of interconnected scientific community. Although considered utopic, this approach to scholarly publishing contributed firmly to the growth and validation of scientific knowledge and to technological progress.

Despite intending to promote cooperation between scientists, scholarly publications have not always been freely available to all, with subscription journals traditionally charging readers with subscription fees or pay-per-article fees.

However, the traditional willingness to distribute science for free, particularly research funded by public funding, alongside with the emergence of the internet, inspired the appearance of the Open Access (OA) movement, which intended to achieve unrestricted online access to articles. ${ }^{1}$

OA emerged in the beginning of the 1990's, but it was only after 2000, with the launch of the Budapest Open Access Initiative, that OA saw its exponential growth. ${ }^{1,2}$ To allow readers' free access to content, some OA journals then adopted an author-pays model, charging the author with article processing charges (APC), which changed the core of the publishing business that was initially focused on readers.

Nevertheless, open access publishing had an unpredictable detrimental side-effect: the corruption of the OA model, with some journals starting to prey on academics via article submissions to obtain financial profit. These are the so-called predatory journals that do not have a rigorous peer-review process and do not follow international norms concerning ethics and quality standards. ${ }^{3}$ Although predatory journals work on an OA basis, it is important to emphasize that not all OA journals have a predatory nature and that some of them have excellent quality and prestigious scientific impact.

Predatory journals offer an increasingly fast publication in exchange of very low APC (median $\$ 100$ ), especially when compared to legitimate $O A$ and subscription-based journals. ${ }^{4}$ To obtain manuscript submissions and to pretend to have scientific credibility, they use aggressive marketing strategies. Through massive e-mail campaigns, predatory journals invite individuals and institutions to submit their papers, highlighting the easiness of publication in the respective journal. They also use a name that is similar to other reputable journals. ${ }^{4}$

Although considered a reality from low- or middleincome countries, a recent study found that more than half of the corresponding authors of a sample of nearly 2000 biomedical articles from more than 200 journals are from high- and upper-middle-income countries. ${ }^{5}$

Most predatory journals are not indexed in appropriate databases, which renders the access to published literature more difficult, leading to eventual waste of published research, and they also use non-reliable journal-level metrics. ${ }^{4}$ Besides, some of them have fake editorial boards or recruit academics indiscriminately or without their permission, which underlines a negligence of the importance of editors as decision-makers, who are intended to guarantee the integrity, quality and transparency of scholarly publishing. ${ }^{4,6}$

\section{Why did predatory journals thrive?}

Predatory practices have been growing quickly, from a total of 1800 journals in 2010 to 8000 journals in $2014 .^{7}$

There were three determining factors for it to thrive: 1) the appearance of the author-pays model applied by

\footnotetext{
1. Editor-in-Chief year 2017. AMP-Student. Lisbon. Portugal.

2. Medical Student. NOVA Medical School. Faculdade de Ciências Médicas. Lisbon. Portugal.

3. Editor-in-Chief year 2018. AMP-Student. Lisbon. Portugal.

4. Associate Editor. AMP-Student. Lisbon. Portugal.

5. Medical Student. Faculdade de Medicina. Universidade de Lisboa. Lisbon. Portugal.

6. Junior doctor. Centro Hospitalar Lisboa Central. Lisbon. Portugal.

7. Department of Otolaryngology. Egas Moniz Hospital. Centro Hospitalar de Lisboa Ocidental. Lisbon. Portugal.

8. NOVA Medical School. Faculdade de Ciências Médicas. Lisbon. Portugal.

$\triangle$ Autor correspondente: Joana Revés. joanareves94@gmail.com

Recebido: 17 de outubro de 2017 - Aceite: 25 de janeiro de 2018 | Copyright @ Ordem dos Médicos 2018
} 
some OA journals; 2) a change in editorial and peer-review processes of some OA publishers, that allowed for the appearance of journals without a clear scope of publishing, whose evaluation criteria are exclusively focused on scientific validity, the manuscripts' relevance for the field and 3) the imposition of a culture of "publish-or-perish".

Therefore, although research funders and academic institutions were not directly responsible for the appearance of predatory publishing, they also contributed to it, by imposing a scientific culture that tends to value the number of publications rather than their quality. The same applies to authors, who started using this type of journals as a mean to publish quickly and easily, without deeply scrutinizing their work, undermining the role of peer-review as a gatekeeper in science.

\section{How can we tackle predatory publishing?}

Jeffrey Beall, a librarian of the University of Colorado, leaded the public exposure of the predatory journals, by developing a blog where he exposed a list of publishers and journals considered unethical. ${ }^{8}$ This content was taken offline at the beginning of 2017 , but its last listing remains available in web archives.

Tackling predatory practices may be a hard task, but not an impossible one. A multistep strategy involving all scientific stakeholders should be settled and should be based on the following principles:

1) Raise awareness to the problem

Exposing predatory practices to raise awareness to their impact is a primordial step in tackling this industry. Reputable journals should increase report of predatory practices. Social media could also play a role by sharing author's experiences with predatory publishing. ${ }^{9}$

2) Development and dissemination of strategies to identify predatory journals

To discriminate predatory journals from 'benign' OA journals is a challenge. Different studies and experts' committees have made guidelines and tools to help authors distinguishing them. Shamseer recognized 13 items that can help identifying predatory journals, such as their scope of interest, publication fees, retraction policies, public presentation, submission guidelines and journal-level metrics ${ }^{4}$. Recognized scholarly organizations also produced the "Principles of Transparency and Best Practice in Scholarly Publishing", which help to evaluate the legitimacy of journals and publishers. ${ }^{10}$ Most recently, the World Association of Medical Editors (WAME) developed an algorithm to discriminate predatory journals from legitimate ones, using a compilation of Beall's characteristics of potential problematic journals, the Directory of Open Access Journals list and features from the "Think Check Submit." website. ${ }^{2}$

3) Development of educational campaigns on publication literacy

Although the mentioned tools can help identifying predatory journals, ascertaining the credibility of a journal is mostly a subjective 'homework' that should be done by authors, since they are the leading victims of the cyber-attacks through which predatory journals advertise themselves. One should assume a journal is predatory until finding evidence that it is not. Therefore, campaigns on publication literacy, providing training and mentorship on scientific writing, publishing ethics and highlighting the value of peer review, should be developed.

\section{4) Changing the paradigm of science}

Although some authors are deceived by the information shared by predatory journals, others consciously publish in this kind of journals. Authors should be aware that publishing an article on a predatory journal can have a harmful effect on their careers.

Science needs to shift the paradigm on which it stands right now and value the quality of publications, rather than their number. Evaluation entities should scrutinise the journals where the articles were published, and also analyse their clinical and scientific relevance.

It is also fundamental to foster a culture of 'responsible metrics' in all the research community. Metrics should be developed and incorporated but always regarded as a complement to peer-review processes on evaluating the scientific production of research units and scientists. Altogether, this would likely break the tendency to 'game' indicators and lead to a return to a more 'knowledgedriven' research enterprise, instead of the current 'impact factor-driven' research, which keeps room for the predatory industry to thrive. Investment in research evaluation is essential in order to make research better.

\section{CONCLUSION}

Issues of illegitimate publishing concern all stakeholders of scholarly publishing, who should develop local and global initiatives to guarantee quality in science communication and protect medical literature. By acknowledging the students' point-of-view on the subject, we propose a multistep strategy focused on raising awareness to the problem, developing and disseminating strategies to identify predatory journals, promoting educational campaigns on publication literacy and changing the paradigm of science to help reducing predatory practices.

\section{ACKNOWLEDGEMENTS}

The authors would like to thank Jocalyn Clark for her contribution and scientific revision of the manuscript.

\section{TRANSPARENCY DECLARATION}

Although the authors are members of the Editorial Board of Acta Médica Portuguesa, this manuscript was developed independently and it does not represent an official statement of the journal. The authors also declare that the manuscript was submitted to peer-review and that the reviewing process was transparent and independent. 


\section{REFERENCES}

1. Laakso M, Welling P, Bukvova H, Nyman L, Björk B, Hedlund T. The Development of Open Access Journal Publishing from 1993 to 2009. PLoS One. 2011;6:e20961.

2. Budapest Open Access Initiative. 2002 [consultado 2017 set 14]. Disponível em: http://www.budapestopenaccessinitiative.org/read

3. Laine C, Winker MA. Identifying predatory or pseudo-journals. World Association of Medical Editors; 2017. [consultado 2017 ago 30]. Disponivel em: http://www.wame.org/identifying-predatory-or-pseudojournals.

4. Shamseer L, Moher D, Maduekwe, Turner L, Barbour V, Burch R, et al. Potential predatory and legitimate biomedical journals: can you tell the difference? A cross-sectional comparison. BMC Med. 2017;15:28.

5. Moher D, Shamseer L, Cobey KD, Lalu MM, Galipeau J, Avey MT, et al.
Stop this waste of people, animals and money. Nature. 2017;549:23-5.

6. Pisanski K. Predatory journals recruit fake editor. Nature. 2017;543:4813.

7. Shen C, Björk B. "Predatory" open access: a longitudinal study of article volumes and market characteristics. BMC Med. 2015;13:230.

8. Beall J. Predatory publishers are corrupting open access. Nature. 2012;489:179-9.

9. Clark J, Smith R. Firm action needed on predatory journals. BMJ. 2015;350:h210.

10. COPE/DOAJ/ OASPA/WAME. Principles of transparency and best practice in scholarly publishing. 2014. [consultado 2017 set 17] Disponível em: http://publicationethics.org/files/u7140/Principles_of_ Transparency_and_Best_Practice_in_Scholarly_Publishing.pdf. 